\title{
Non-steroidal anti-inflammatory drug-induced jejunal and colonic diaphragm disease: a report of two
}

\section{cases}

\author{
I W Fellows, J M F Clarke, P F Roberts
}

West Norwich Hospital, and Norfolk \& Norwich Hospital, Norwich I W Fellows

J M F Clarke

P F Roberts

Correspondence to:

Dr I W Fellows, West

Norwich Hospital, Bowthorpe

Road, Norwich NR2 3TU

Accepted for publication

10 December 1991

\begin{abstract}
Two patients with intestinal submucosal diaphragm disease associated with non-steroidal anti-inflammatory drugs are presented. The jejunum was affected in one, and in the other the ascending colon. Most previously reported cases have shown ileal disease and no case to date has shown involvement of the colon. The reasons for the localisation of these diaphragms remain unclear.

(Gut 1992; 33: 1424-1426)
\end{abstract}

It is clear that non-steroidal anti-inflammatory drugs (NSAIDs) can cause a range of abnor-

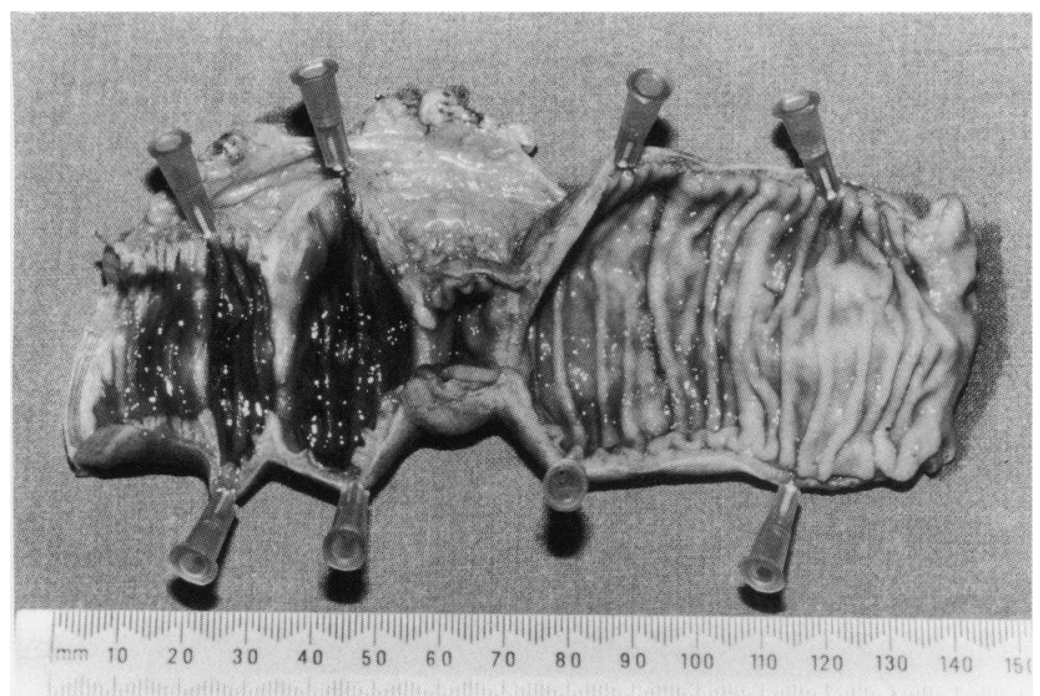

Figure 1: Segment of resected jejunum showing four diaphragm strictures.

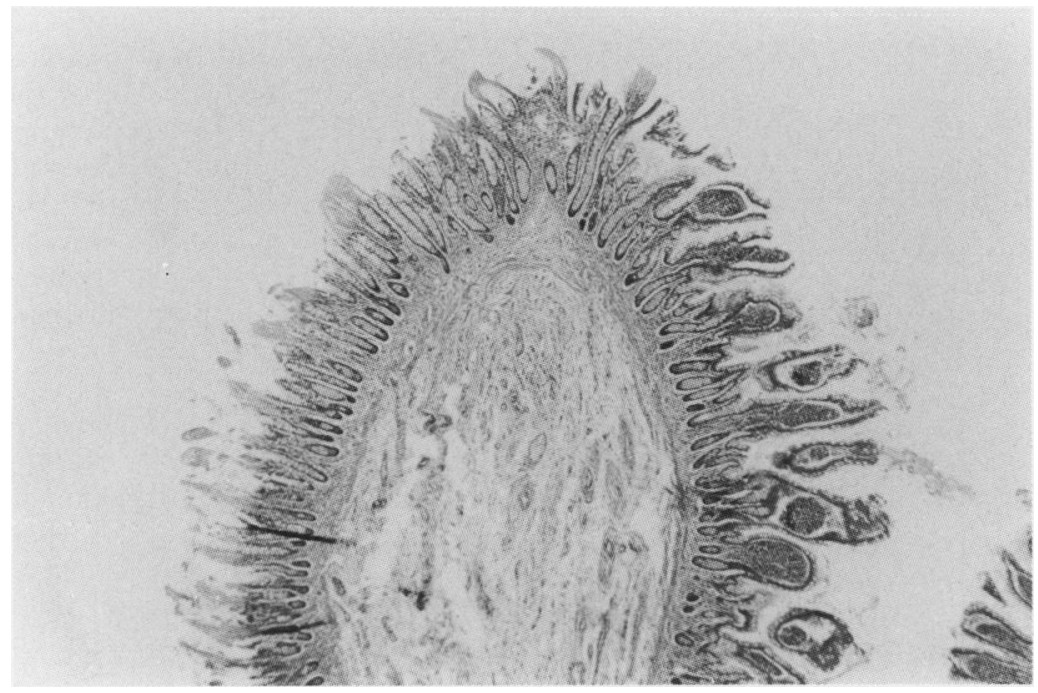

Figure 2: Section through the tip of one of the jejunal diaphragms. (Haematoxylin and eosin, original magnification $\times 20$.) malities in the small intestine ${ }^{1}$ including, rarely, stenoses caused by submucosal fibrosis. However, all the seven patients reported by Lang et $a l^{2}$ showed stenoses of the ileum. In the present study, two patients are presented in whom NSAID resulted in stenoses of the jejunum and ascending colon, respectively.

\section{Case reports}

CASE 1

A 69 year old woman presented with a five week history of anorexia, weight loss of $6 \mathrm{~kg}$, nausea, vomiting, and abdominal bloating. Seven years previously, she had been diagnosed as having seropositive rheumatoid arthritis and Sjogren's syndrome. She began treatment with ibuprofen and later diclofenac, and within one year developed an iron deficiency anaemia of $8 \cdot 3 \mathrm{~g} / \mathrm{dl}$. This was treated with iron tablets and later intramuscular injections of iron but she remained moderately anaemic. Gastroscopy showed a benign prepyloric ulcer but the patient declined a barium enema and further investigation was not performed. Over the succeeding seven years, she received fenbrufen, ibuprofen, tiaprofenic acid, and flurbiprofen sequentially, using the latter as the sole NSAID for five years. There was no overt gastrointestincal bleeding. Physical examination showed a thin woman of $40 \mathrm{~kg}$ with obvious rheumatoid arthritis. Abdominal examination, rectal examination, and sigmoidoscopy to $20 \mathrm{~cm}$ were normal. A barium enema was normal. Gastroscopy showed a small inflammatory ulcer at the junction of the first and second parts of the duodenum, confirmed by biopsy.

The patient's haemoglobin concentration was $10.3 \mathrm{~g} / \mathrm{dl}$, mean cell volume 61.5 (normal 80-100), white cell count $6.6 \times 10^{9} / 1$, platelets $616 \times 10^{\%} / 1$, and ferritin $19 \mu \mathrm{g} / \mathrm{l}$ (normal 23-300). Serum vitamin $\mathrm{B} 12$ and red cell folate concentrations were normal. Serum glucose, electrolyte, urea, and creatinine concentrations were normal as were biochemical liver function tests.

Fine bore nasogastric tube feeding was begun but within one week, she developed vomiting, abdominal distension with visible peristalsis and constipation. Plain abdominal radiology showed dilated small intestinal loops. A provisional diagnosis of small bowel obstruction due to NSAID induced stenosis was made. After a period of no oral intake, intravenous feeding and parenteral iron therapy, during which the signs of intestinal obstruction resolved, a laparotomy was performed. This showed four strictures of the jejunum (Fig 1), which were excised with 
Figure 3: Barium enema showing a short stricture in the ascending colon (arrowed).

Figure 4: Section through a broad based mucosal diaphragm in the ascending colon. (Haematoxylin and eosin, original magnification $\times 20$.)

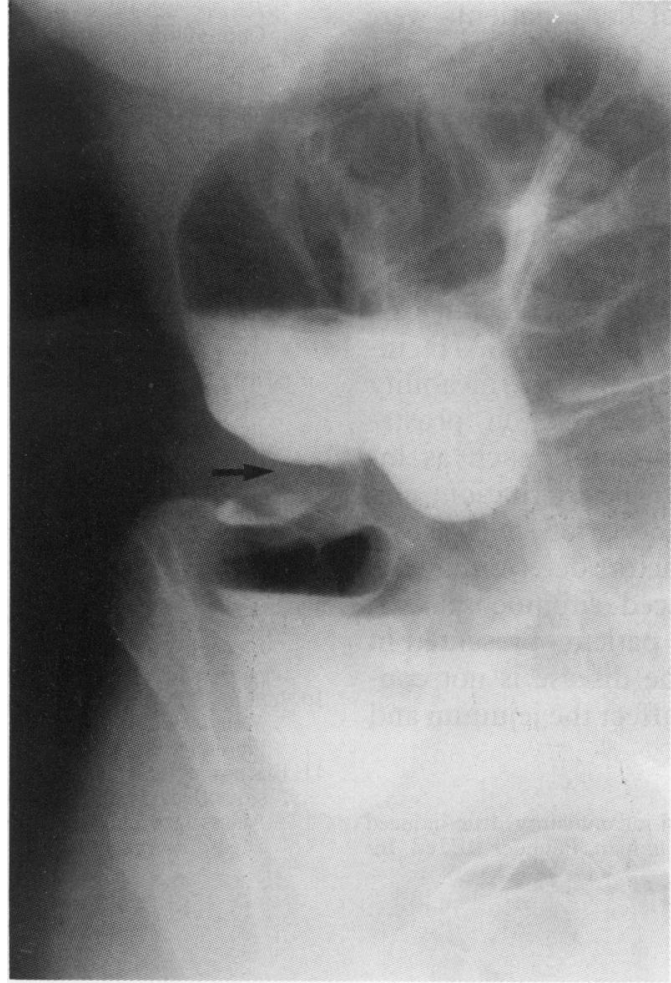

primary anastamosis of the bowel. The patient made an uneventful recovery. NSAIDs were stopped and four moths later she was well with a haemoglobin concentration of $12.5 \mathrm{~g} / \mathrm{dl}$.

Macroscopical examination of the strictures showed the typical appearances of diaphragm disease. The mucosal folds of the diaphragm were supported by proliferation of longitudinal bands of thickened and splayed muscularis mucosae extending into the submucosa. Bands of smooth muscle also extended into the lamina propria at the tip of the stricture (Fig 2). In places the overlying glands showed pyloric gland metaplasia caused by previous ulceration. Broader based mucosal folds were also seen. There was no evidence of coeliac disease.

CASE 2

A 77 year old woman complained of loss of appetite and weight loss of $12 \mathrm{~kg}$ in 6 months. She had not suffered abdominal pain but had been constipated, opening her bowels every 3-7 days for about two years. Rarely, she noted a little red blood on the paper after defecation.

She had suffered from polyarthritis for about 20 years and had taken slow release diclofenac $100 \mathrm{mg}$ once daily for five years. Physical examination showed koilonychia and deformity of the hands consistent with rheumatoid arthritis. Abdominal examination showed a surgical scar of vagotomy and pyloroplasty for duodenal ulceration 16 years previously. The descending colon was palpable because of faeces. Rectal examination and rigid sigmoidoscopy were normal.

She had developed a hypochromic microcytic anaemia of $8.8 \mathrm{~g} / \mathrm{dl}$, which responded to iron injections given by her general practitioner. Serum urea, electrolytes, creatinine, and liver function tests were normal. Barium enema showed a few sigmoid diverticula and a short stricture of the ascending colon (Fig 3). Laparotomy confirmed a short stricture of the ascending colon and a right hemicolectomy was performed. The patient made an uneventful recovery.

The right hemicolectomy specimen showed several sirictures at the origin of the ascending colon characterised by irregular, partly annular, mucosal folds. Microscopical examination showed that these broad based mucosal folds were almost identical to the jejunal lesions in the previous case with hyperplastic splayed muscularis mucosae extending into the lamina propria and submucosa (Fig 4). These features have not previously been described in the colon.

\section{Discussion}

The two patients presented had suffered iron deficiency anaemia and had taken NSAIDs for protracted periods. The proliferation of muscularis mucosae into the lamina propria of the mucosal folds and extension into the submucosa in these two patients was similar to that described as caused by NSAIDs ${ }^{2}$ but the location, in the jejunum and ascending colon, respectively contrasts with the ileal involvement in the patients of Lang et al. ${ }^{2}$

Similar strictures, mainly affecting the jejunum, were reported in a patient with coeliac disease ${ }^{3}$ although it is not known whether the patient had taken NSAIDs. Mucosal diaphragms in the duodenum and jejunum of patients with coeliac disease have also been described. ${ }^{4}$ However, there was no evidence of coeliac disease in patient 1 in the present study. Jejunal stricture was reported in one patient taking oral indomethacin for five years ${ }^{5}$ and distal jejunal strictures were reported ${ }^{6}$ in NSAID users.

Large intestinal effects of NSAIDs include inflammation, bleeding, ulceration, and perforation..$^{78}$ Although the latter authors ${ }^{8}$ cite colonic strictures as a side effect of NSAIDs, they provide no specific references for this observation. The effects of NSAIDs on the large intestine are largely based on anecdotal cases. De Vos et $\mathrm{al}^{9}$ found mild acute colitis in colonoscopic biopsy specimens of only 1 of 27 patients with rheumatoid arthritis submitted to ileocolonos- 
copy. They stated most of these patients were taking NSAIDs but did not provide any other details of drug consumption and excluded any effect of NSAIDs in colonic inflammation. Recently, Jenkins et $a l^{10}$ showed that NSAIDs increased colonic permeability to ${ }^{51}$ chromium labelled ethylenediamine tetra-acetate.

The mechanisms underlying the induction of intestinal damage by NSAIDs remain unclear, although the amelioration of the NSAID induced increase in small intestinal permeability by misoprostol implicates effects on prostaglandin synthesis. ${ }^{11}$ Other factors such as increased lysosomal fragility, local irritation, and impaired oxidative phosphorylation, may also be involved. "Similarly, the factors determining the location of NSAID induced submucosal diaphragms are unclear. The patients presented in this paper indicate that the disease is not confined to the ileum but can affect the jejunum and colon.

1 Bjarnason I. Non-steroidal anti-inflammatory drug-induced small intestinal inflammation in man. Pounder RE, ed. In
Recent advances in gastroenterology. 7th. Edinburgh: Churchill Livingstone, 1988: 23-46.

2 Lang J, Price AB, Lein AJ, Burke M, Gumpel JM, Bjarnason I. Diaphragm disease: pathology of disease of the small intestine induced by non-steroidal anti-inflammatory drugs. intestine induced by non-steroid

3 Cook WT, Holmes GKT. The jejunal mucosa. In: Cooke WT, Holmes GKT, eds. Coeliac disease Edinburgh: Churchil Livingstone, 1984: 23-66.

4 Thompson H. Pathology of coeliac disease. In Morson BC, ed. Pathology of the gastro-intestinal tract. Berlin: Springer Verlag, 1976: 49-75.

5 Sturges HF, Krone CL. Ulceration and stricture of the jejunum in a patient on long-term indomethacin therapy. Am f Gastroenterol 1973; 59: 162-9.

6 Bjarnason I, Price AB, Zarelli G, Smethurst P, Burke M, Giuysel JM, Lein AJ. Clinicopathological features of nonsteroidal anti-inflammatory drug-induced small intestine steroidal anti-inflammatory drug-induced
strictures. Gastroenterology 1988;94: 1070-4.

7 Uribe A, Johansson C, Slezak P, Rubio C. Ulcerations of the colon associated with naproxen and acetylsalicylic acid treatment. Gastrointest Endosc 1986; 32: 242-4.

8 Aabakken L, Osnes $M$. Non-steroidal anti-inflammatory drug-induced disease in the distal ileum and large bowel Scand $\mathcal{F}$ Gastroenterol 1989; 24 (suppl 163): 48-55.

9 De Vos M, Cuvelier C, Mielants H, Veys E, Barbier F Elewaut A. Ileocolonoscopy in seronegative spondylarthropathy. Gastroenterology 1989; 96: 339-44.

10 Jenkins AP, Trew DR, Crump BJ, Nukajam WS, Foley JA, Menzies IS, et al. Do non-steroidal anti-inflammatory drugs increase colonic permeability? Gut 1991; 32: 66-9.

11 Bjarnason I, Macpherson A. The changing gastrointestinal side effect profile of non-steroidal anti-inflammatory drugs. A new approach for the prevention of a new problem. Scand $\mathcal{f}$ Gastroenterol 1989; 24 (suppl 163): 56-64. 